\title{
Associations of Sperm mtDNA copy number, DNA fragmentation index, and reactive oxygen species with clinical outcomes in ART treatments
}

Wei-Hui Shi

Shanghai Jiao Tong University School of Medicine

Mu-Jin Ye

Shanghai Jiao Tong University School of Medicine

Zhi-Yang Zhou

Shanghai Jiao Tong University School of Medicine

Ning-Xin Qin

Tongji University School of Medicine

Xuan-You Zhou

Shanghai Jiao Tong University School of Medicine

Nai-Xin Xu

Shanghai Jiao Tong University School of Medicine

\section{Song-Chang Chen}

Shanghai Red House Obstetrics and Gynecology Hospital: Obstetrics and Gynecology Hospital of Fudan

University

Shu-Yuan Li

Shanghai Jiao Tong University School of Medicine

Chen-Ming Xu ( $\sim$ chenming_xu2006@163.com)

International Peace Maternity and Child Health Hospital

\section{Research}

Keywords: sperm concentration, motility, morphology, MtDNA-CN, DFI, ROS, assisted reproductive technology (ART), computer assisted sperm analysis (CASA)

Posted Date: August 2nd, 2021

DOI: https://doi.org/10.21203/rs.3.rs-757522/v1

License: (c) (i) This work is licensed under a Creative Commons Attribution 4.0 International License.

Read Full License 
Version of Record: A version of this preprint was published at Frontiers in Endocrinology on March 23rd, 2022. See the published version at https://doi.org/10.3389/fendo.2022.849534. 


\section{Abstract \\ Background}

Except for sperm parameters (sperm concentration, motility, and morphology), sperm mitochondria DNA copy number (mtDNA-CN), DNA fragmentation index (DFI), and reactive oxygen species (ROS) content are essential characteristics for sperm function. However, the roles of these measurements in embryo development and pregnancy outcomes are still unclear.

\section{Methods}

Semen samples of 402 participants were collected. Sperm parameters, including sperm morphology, concentration, and motility, were analyzed by a computer-assisted sperm analysis system. MtDNA-CN, $\mathrm{DFI}$, and ROS levels were measured using remained sperms through quantitative polymerase chain reaction method, sperm chromatin structure assay and Reactive Oxygen Species Assay Kit, respectively. The assisted reproductive technology (ART) treatments, including in vitro fertilization (IVF) and intracytoplasmic sperm injection (ICSI), were performed in 126 couples of these participants.

\section{Results}

In 402 semen samples, elevated mtDNA-CN and DFI were associated with poor seminal quality. In 126 couples conducted ART, only mtDNA-CN was negatively correlated with fertilization rate in ART cases. However, it was not significant after adjusting male age, female age, seminal quality, and ART strategy. With regard to pregnancy outcomes, none of sperm mtDNA-CN, ROS and DFI was associated with clinical pregnancy rate in 79 cases transferred embryos.

\section{Conclusions}

Increased mtDNA-CN and DFI in sperms jointly contributed to poor seminal quality. However, none of sperm mtDNA-CN, ROS/MS and DFI were associated with clinical outcomes in ART.

\section{Introduction}

It is estimated that over 186 million people are affected by infertility, and assisted reproductive technology (ART) treatments are increasing continuously worldwide[1]. However, there is a challenge that a large proportion of embryos during ART are ended with adverse outcomes such as implantation failure and miscarriage[2]. Abnormal gametes from parents were both found to impact embryo quality and the effect of paternal factors has been increasingly explored in recent years[3, 4]. 
Previous studies have investigated the associations between seminal quality, including parameters of sperm concentration, motility and morphology, and ART outcomes. It was reported that sperm concentration and motility were both correlated strongly with the fertilization rate, and poor seminal quality might lead to developmental failure of embryos, mainly manifested as blastomere fragmentations[5]. Nevertheless, embryos fertilized with intracytoplasmic sperm injection (ICSI) were barely affected by sperm concentration and morphology. It seems that sperm motility plays a more significant role in embryo development[6].

Currently, researchers gradually pay attention to the relationship between sperm abnormalities and adverse pregnancy outcomes[7-9]. Sperm mitochondria are essential to the normal reproductive process as they are involved in multiple functions, including the production of adenine triphosphate and reactive oxygen species (ROS), as well as the regulation of apoptosis[10]. Oxidative stress induced by excess ROS in sperms have been found to impair the DNA demethylation in paternal pronucleus and affect embryo development[8]. Negative associations were observed between seminal ROS and fertilization and pregnancy rate after IVF[11]. Additionally, as a biomarker of mitochondrial function and a relative measure of mtDNA content, the level of sperm mitochondrial DNA copy number (mtDNA-CN) has been reported significantly negative correlated with the fertilization rate [12]. Rosati et al. found that higher sperm mtDNA-CN was associated with lower pregnancy probability in couples without contraception, indicating mtDNA might be a potential clinical biomarker to predict male fecundity[13]. Moreover, mitochondrial dysfunction is potentially related to acrosome reaction, acrosin activity, and sperm chromatin integrity[14]. As an indicator of sperm chromatin integrity, DNA fragmentation index (DFI) was suggested to have a negative correlation with embryo development and implantation rate in ICSI cycles [9]. However, another study suggested that sperm DFI had no association with embryo quality and pregnancy outcomes[15].

Generally, whether measurements reflecting sperm nucleal function (DFI) and mitochondrial function (ie. mtDNA-CN and ROS) would be predictive to ART outcomes remain unclear. Hence, this study aims to investigate the effects of sperm mtDNA-CN, ROS, and DFI on the reproductive process, including male fertility, embryo viability and pregnancy outcomes.

\section{Method}

\section{Subjects}

In this study, all the participants were recruited during July 2020 to September 2020 from the outpatient department of reproductive center in the International Peace Maternity \& Child Health Hospital (IPMCH), Shanghai Jiao Tong University School of Medicine. Males were included when they met the criteria: 1). 20-50 years of age; 2 ). without $A Z F$ gene microdeletions; 3 ). without mycoplasma or chlamydia infections; 4). without medication taken within three months. Semen samples were collected by masturbation after 3-7 days of sexual abstinence. Written consent forms were obtained from all 
participants. This study was approved by the IPMCH Ethics Review Committee and performed according to the Declaration of Helsinki.

\section{Semen analysis and sperm chromatin structure assay}

After liquefaction, sperm parameters, including sperm morphology, concentration, and motility, were assessed by the computer assisted sperm analysis (CASA) system according to the World Health Organization (WHO) laboratory manual[16]. Sperm DFI was determined by sperm chromatin structure assay[8]. In detail, sperm samples were diluted to a concentration of $2 \times 10^{6} / \mathrm{ml}$ with TNE buffer $(0.01 \mathrm{M}$ Tris- $\mathrm{HCl}, \mathrm{pH} 7.4,0.15 \mathrm{M} \mathrm{NaCl}, 1 \mathrm{mM}$ EDTA) firstly. Then $100 \mu$ ldiluted sperm suspension was mixed with $200 \mu$ l acid-detergent solution ( $\mathrm{pH} 1.2,0.08 \mathrm{~N} \mathrm{HCl}, 0.15 \mathrm{M} \mathrm{NaCl}, 0.1 \%$ Triton X-100) and incubated for $30 \mathrm{~s}$ on ice. After adding $600 \mu \mathrm{l}$ acridine orange solution into the sample, it was incubated for $3 \mathrm{~min}$, and tested by NovoCyte Flow Cytometer (Agilent, California, USA).

\section{Sperm DNA extraction}

For sperm DNA isolation, samples were washed three times with $1 \times$ PBS, centrifuged at $200 \mathrm{~g}$ for 5 min. Somatic cells were eliminated with $0.1 \%$ sodium dodecyl sulfate (3250GR500, BioFroxx) and $0.5 \%$ Triton ${ }^{\mathrm{TM}}-\mathrm{X} 100$ (X100, Sigma) in DEPC-treated water (AM9920, Invitrogen) at $4^{\circ} \mathrm{C}$ for $15 \mathrm{~min}$. Then the spermatozoa were homogenized with $1 \mathrm{~mm}$ beads in ALT buffer (69504, Qiagen) containing $10 \mathrm{mg} / \mathrm{ml}$ Proteinase K and 150 mM DL-Dithiothreitol (A100281, Sangon Biotech, China). Total DNA was extracted using the DNeasy Blood \& Tissue Kit (69504, Qiagen) following the manufacturer's instructions.

\section{Quantification of mtDNA copy number}

The mtDNA-CN was measured by a quantitative polymerase chain reaction (qPCR) method using a QuantStudio $^{\text {TM }} 7$ Flex real-time PCR machine (4485701, Applied Biosystems)[17]. Briefly, the primers of the Taqman assay were designed in a stable segment in the minor arc of mtDNA (mtMinArc) and RNAse $\mathrm{P}$ (4403326, ThermoFisher, USA) was chosen as the genomic DNA reference. Detailed primer sequence was shown in Supplementary Table S1. Real-time PCR with three technical replicates were performed as previously described[17]. The mtDNA-CN was calculated using the following formulae: mtDNA-CN $=2 \triangle C T$ $($ mtDNA-CN $)$, where $\triangle \mathrm{CT}(\mathrm{mtDNA}-\mathrm{CN})=\mathrm{CTRNase} \mathrm{P}-\mathrm{CTmtMinArc}$.

\section{Determination of sperm ROS levels}

Sperm ROS content was measured by Reactive Oxygen Species Assay Kit (S0033M, Beyotime Biotech, Shanghai, China) following the manufacturer's instructions. Collected sperm samples were washed three times with 1 x PBS $(200 \mathrm{~g}, 5 \mathrm{~min})$ and then incubated with 2',7'-Dichlorodihydrofluorescein diacetate (DCFH-DA, $10 \mu \mathrm{mol} / \mathrm{L}$ ) at $37^{\circ} \mathrm{C}$ for 20 mins. Then the samples were washed three times with $1 \times$ PBS (200g, $5 \mathrm{~min})$, and the fluorescent signals of DCFH-DA oxidized products (2',7'-dichlorofluorescein, DCF) were detected using Synergy ${ }^{\mathrm{TM}} \mathrm{H} 1$ Microplate Reader (BioTek Instruments, Inc., Winooski, USA) under 488 
$\mathrm{nm}$ excitation. To normalize the ROS level, ROS per million sperms (ROS/MS) was represented the average ROS content in each seminal sample.

\section{Outcome assessment}

In terms of ART, only those IVF/ICSI cycles performed within three months after the semen analysis were included. The embryonic outcomes included fertilization rate, cleavage rate and top-quality embryo rate. The fertilization rate was the percentage of fertilized embryos in retrieved oocytes. The cleavage rate was the percentage of 2-cell embryos in all fertilized embryos. The cleaving embryos on Day 3 was classified into Grade 1 to 5 according to the numbers and sizes of blastomeres and the percentage of cytoplasmic fragments[18]. The top-quality embryo rate was the percentage of embryo evaluated as Grade 1 or 2 in all fertilized embryos. When embryos were transferred, pregnancy outcomes were observed in every transfer cycle. Clinical pregnancy was defined as the presence of an intrauterine gestational sac by ultrasound examination at a gestational age of 7 weeks.

\section{Statistical analysis}

Characteristics of participants were summarized. Continuous variables were expressed using the median (inter-quartile range) and compared with the Mann-Whitney $U$ test. Categorical variables were described with percentages and compared using the Chi-square test. The correlations between male age, mtDNACN, ROS/MS, DFI and sperm parameters were analyzed with Spearman's rank correlation. To further investigate their relationships, seminal quality was categorized as normal or abnormal sperm group according to sperm parameters and analyzed with a binary logistic regression. The sample that at least one parameter among sperm concentration, motility and morphology lowered than the criteria was categorized as abnormal sperm group. The associations between mtDNA-CN, ROS/MS, DFI and embryonic outcomes were analyzed with linear regression, respectively. The generalized linear model (GLM) was performed to adjust the covariates, including male age, female age, seminal quality, and ART

strategy. Pregnancy outcomes were analyzed with generalized estimating equations (GEE) to address the correlation of different transfer cycles in the same patient. Variates in the model were yielded with odds ratios (OR) and 95\% confidence intervals (Cls). All statistical analyses were conducted with SPSS statistics 24 (IBM, Chicago, USA).

\section{Result}

\section{Clinical characteristic}

During the study period, 402 male participants fulfilled the inclusion criteria were included in our study. Among them, 126 with their spouses were subjected to IVF within three months after the semen analysis in our center. Conventional sperm parameters, also as known as seminal quality, and three measurements, mtDNA-CN, ROS/MS and DFI, in all participants and ART cases are presented in Table 1. Compared to the IVF cases, the ICSI cases showed lower total motility and higher DFI levels $(P<0.05)$. 
Table 1

Sperm parameters and measurements in all participants and ART cases

\begin{tabular}{|c|c|c|c|c|}
\hline & $\begin{array}{l}\text { All participants ( } \mathrm{n} \\
=402 \text { ) }\end{array}$ & $\begin{array}{l}\text { IVF cases }(n= \\
82)\end{array}$ & $\begin{array}{l}\text { ICSI cases }(n= \\
44)\end{array}$ & $P^{*}$ \\
\hline Male age, years & $33(31,37)$ & $33(30,36)$ & $35.5(32,40)$ & 0.009 \\
\hline Female age, years & & $33(29,36)$ & $34(31,38)$ & 0.080 \\
\hline $\begin{array}{l}\text { Percentage of male with } \\
\text { abnormal sperms }\end{array}$ & $71 \%$ & $55 \%$ & $59 \%$ & 0.708 \\
\hline Morphology, \% & $3(2,4)$ & $3(2,4)$ & $3(1,4)$ & 0.244 \\
\hline $\begin{array}{l}\text { Sperm concentration, } \\
\mathrm{million} / \mathrm{ml}\end{array}$ & $\begin{array}{l}36.99(21.39 \\
59.04)\end{array}$ & $\begin{array}{l}40.62(26.21 \\
60.11)\end{array}$ & $\begin{array}{l}36.26(18.85 \\
53.64)\end{array}$ & 0.250 \\
\hline Total motility, \% & $\begin{array}{l}41.90(26.88 \\
52.30)\end{array}$ & $\begin{array}{l}42.95(29.75 \\
51.60)\end{array}$ & $\begin{array}{l}34(17.65 \\
49.05)\end{array}$ & 0.014 \\
\hline mtDNA-CN & $3.80(2.11,7.45)$ & $\begin{array}{l}3.30(1.96, \\
8.36)\end{array}$ & $\begin{array}{l}4.37(2.39 \\
9.07)\end{array}$ & 0.321 \\
\hline ROS/MS & $\begin{array}{l}81.41(48.73 \\
175.30)\end{array}$ & $\begin{array}{l}74.15(49.89 \\
146.10)\end{array}$ & $\begin{array}{l}73.00(47.23 \\
154.66)\end{array}$ & 0.976 \\
\hline DFI & $9.92(5.62,15.92)$ & $\begin{array}{l}7.98(5.16 \\
14.56)\end{array}$ & $\begin{array}{l}11.83(6.59 \\
22.71)\end{array}$ & 0.005 \\
\hline
\end{tabular}

\section{Associations of sperm mtDNA-CN, DFI, and ROS with seminal quality}

Based on the 5th WHO laboratory manual[16], the seminal quality were divided into two groups: the normal sperm group $(n=116)$ and the abnormal sperm group $(n=290)$. As shown in Fig. 1 , only the mtDNA-CN (OR 1.103, 95\% Cl 1.042 to $1.166 ; \mathrm{P}=0.001)$ and DFI (OR 1.134, 95\% Cl 1.084 to $1.187 ; \mathrm{P}=$ $5.401 \times 10^{-8}$ ) were associated with seminal quality. Moreover, the correlation analysis showed that ROS/MS and mtDNA-CN were both negatively correlated with three sperm parameters and DFI was inversely associated with sperm motility and morphology (Supplemental Figure S1).

\section{Correlations between sperm mtDNA-CN, DFI, and ROS and embryonic outcomes.}

With regard to the three embryonic outcomes, including fertilization rate, cleavage rate and top-quality embryo rate, a higher sperm mtDNA-CN level was associated with a lower percentage of fertilization rate in all ART cases $(\beta=-0.629,95 \% \mathrm{Cl}-1.175$ to $-0.083 ; P=0.024)$. However, in the IVF or ICSI subgroup analysis, no association was observed (Table 2). There was no significant association between sperm mtDNA-CN and cleavage rate $(\beta=0.108,95 \% \mathrm{Cl}-0.344$ to $0.560 ; P=0.637)$ and top-quality embryo rate ( $\beta$ $=0.345,95 \% \mathrm{Cl}-0.345$ to $1.034 ; P=0.325)$ (Table 2$)$. The quartile analysis showed a similar trend that the fourth quartile group of sperm mtDNA-CN was companied with the lowest fertilization rate (Table 3). 
However, the association between sperm mtDNA-CN and fertilization rate was disappeared after adjusting for male age, female age, seminal quality, and ART strategy (Table 3). Since no significances were present in univariate linear regression analysis, DFI and ROS/MS were not adjusted as covariates. Nevertheless, the female age, seminal quality, and ART strategy were associated with the fertilization rate with the statistically significant odds ratios (Supplemental Table S2).

Table 2

Embryotic outcomes of patients with ART

\begin{tabular}{|c|c|c|c|c|c|c|c|}
\hline & & \multicolumn{2}{|c|}{ Fertilization rate (\%) } & \multicolumn{2}{|c|}{ Cleavage rate (\%) } & \multicolumn{2}{|c|}{$\begin{array}{l}\text { Top-quality embryo } \\
\text { rate (\%) }\end{array}$} \\
\hline & & $\begin{array}{l}\text { Coefficients } \\
(95 \% \mathrm{Cl})\end{array}$ & $P$ & $\begin{array}{l}\text { Coefficients } \\
(95 \% \mathrm{Cl})\end{array}$ & $P$ & $\begin{array}{l}\text { Coefficients } \\
(95 \% \mathrm{Cl})\end{array}$ & $P$ \\
\hline & & $95 \% \mathrm{Cl}$ & & & & & \\
\hline \multirow[t]{3}{*}{$\begin{array}{l}\text { ART } \\
\text { cases }\end{array}$} & $\begin{array}{l}\mathrm{mtDNA}- \\
\mathrm{CN}\end{array}$ & $\begin{array}{l}-0.629(-1.175 \\
-0.083)\end{array}$ & 0.024 & $\begin{array}{l}0.108(-0.344 \\
0.560)\end{array}$ & 0.637 & $\begin{array}{l}0.345(-0.345, \\
1.034)\end{array}$ & 0.325 \\
\hline & DFI & $\begin{array}{l}-0.128(-0.567 \\
0.311)\end{array}$ & 0.564 & $\begin{array}{l}0.127(-0.229 \\
0.483)\end{array}$ & 0.482 & $\begin{array}{l}0.377(-0.165, \\
0.919)\end{array}$ & 0.171 \\
\hline & ROS/MS & $\begin{array}{l}-0.012(-0.035 \\
0.012)\end{array}$ & 0.325 & $\begin{array}{l}0.005(-0.013 \\
0.024)\end{array}$ & 0.566 & $\begin{array}{l}0.009(-0.20 \\
0.038)\end{array}$ & 0.532 \\
\hline \multirow[t]{3}{*}{$\begin{array}{l}\text { IVF } \\
\text { cases }\end{array}$} & $\begin{array}{l}\mathrm{mtDNA}- \\
\mathrm{CN}\end{array}$ & $\begin{array}{l}-0.440(-1.077 \\
0.197)\end{array}$ & 0.173 & $\begin{array}{l}0.060(-0.357 \\
0.478)\end{array}$ & 0.775 & $\begin{array}{l}0.221(-0.670, \\
1.111)\end{array}$ & 0.623 \\
\hline & DFI & $\begin{array}{l}0.260(-0.457 \\
0.977)\end{array}$ & 0.473 & $\begin{array}{l}-0.024(-0.490 \\
0.442)\end{array}$ & 0.919 & $\begin{array}{l}-0.279 \\
(-1.272 \\
0.715)\end{array}$ & 0.578 \\
\hline & ROS/MS & $\begin{array}{l}-0.007(-0.036 \\
0.022)\end{array}$ & 0.624 & $\begin{array}{l}0.002(-0.017 \\
0.020)\end{array}$ & 0.872 & $\begin{array}{l}-0.021 \\
(-0.060 \\
0.019)\end{array}$ & 0.301 \\
\hline \multirow[t]{3}{*}{$\begin{array}{l}\text { ICSI } \\
\text { cases }\end{array}$} & $\begin{array}{l}\mathrm{mtDNA}_{\mathrm{CN}} \\
\end{array}$ & $\begin{array}{l}-0.780(-1.768 \\
0.209)\end{array}$ & 0.119 & $\begin{array}{l}0.242(-0.739 \\
1.224)\end{array}$ & 0.621 & $\begin{array}{l}0.482(-0.675, \\
1.638)\end{array}$ & 0.405 \\
\hline & DFI & $\begin{array}{l}-0.045(-0.714 \\
0.624)\end{array}$ & 0.892 & $\begin{array}{l}0.401(-0.234, \\
1.036)\end{array}$ & 0.210 & $\begin{array}{l}0.658(-0.080, \\
1.397)\end{array}$ & 0.079 \\
\hline & ROS/MS & $\begin{array}{l}-0.013(-0.052 \\
0.027)\end{array}$ & 0.519 & $\begin{array}{l}0.012(-0.026 \\
0.050)\end{array}$ & 0.531 & $\begin{array}{l}0.082(-0.005, \\
0.082)\end{array}$ & 0.082 \\
\hline
\end{tabular}


Table 3

Association of mtDNA-CN with fertilization rate

\begin{tabular}{|c|c|c|c|c|}
\hline \multirow[t]{2}{*}{ mtDNA-CN } & \multicolumn{4}{|l|}{ Fertilization rate } \\
\hline & OR (95\% Cl) & $P$ & Adj OR $(95 \% \mathrm{Cl})^{a}$ & $P$ \\
\hline Q1 & Reference & & & \\
\hline Q2 & $0.919(0.818,1.033)$ & 0.158 & $0.923(0.828,1.030)$ & 0.153 \\
\hline Q3 & $0.928(0.826,1.043)$ & 0.211 & $0.959(0.860,1.069)$ & 0.450 \\
\hline Q4 & $0.870(0.773,0.979)$ & 0.021 & $0.919(0.820,1.029)$ & 0.141 \\
\hline
\end{tabular}

\section{Pregnancy outcomes.}

Until now, only 79 of 126 couples undergoing ART have taken embryo transfer. Totally, 113 embryos were transferred, including 12 fresh embryos and 101 frozen embryos. Three measurements, mtDNA-CN, DFI and ROS/MS, were not associated with clinical pregnancy rate not only in all transfer cycles, but in the IVF or ICSI subgroup (Table 4). 
Table 4

Pregnancy outcomes of patients with embryo transfer

\begin{tabular}{|c|c|c|c|c|c|}
\hline & & \multicolumn{4}{|c|}{ Clinical pregnancy rate } \\
\hline & & OR $(95 \% \mathrm{Cl})$ & $P$ & Adj OR $(95 \% \mathrm{Cl})^{a}$ & $P$ \\
\hline \multirow[t]{3}{*}{$\begin{array}{l}\text { All transfer cycles }(n= \\
113)\end{array}$} & $\begin{array}{l}\mathrm{mtDNA}_{\mathrm{CN}} \\
-\end{array}$ & $\begin{array}{l}1.000(0.947 \\
1.056)\end{array}$ & 0.998 & $\begin{array}{l}0.996(0.938 \\
1.057)\end{array}$ & 0.893 \\
\hline & DFI & $\begin{array}{l}1.012(0.967, \\
1.058)\end{array}$ & 0.610 & $\begin{array}{l}1.005(0.955 \\
1.058)\end{array}$ & 0.839 \\
\hline & ROS/MS & $\begin{array}{l}1.001(0.999 \\
1.004)\end{array}$ & 0.238 & $\begin{array}{l}1.001(0.999 \\
1.004)\end{array}$ & 0.362 \\
\hline \multirow[t]{3}{*}{$\begin{array}{l}\text { IVF transfer cycles }(n= \\
89)\end{array}$} & $\begin{array}{l}m_{\mathrm{CN}} \\
\mathrm{CN}\end{array}$ & $\begin{array}{l}0.988(0.928 \\
1.052)\end{array}$ & 0.709 & $\begin{array}{l}0.975(0.911 \\
1.044)\end{array}$ & 0.473 \\
\hline & DFI & $\begin{array}{l}0.960(0.894 \\
1.032)\end{array}$ & 0.268 & $\begin{array}{l}0.971(0.896 \\
1.051)\end{array}$ & 0.462 \\
\hline & ROS/MS & $\begin{array}{l}1.001(0.998 \\
1.003)\end{array}$ & 0.487 & $\begin{array}{l}1.001(0.998 \\
1.004)\end{array}$ & 0.516 \\
\hline \multirow[t]{3}{*}{$\begin{array}{l}\text { ICSI transfer cycles }(n= \\
24)\end{array}$} & $\begin{array}{l}\mathrm{mtDNA}- \\
\mathrm{CN}\end{array}$ & $\begin{array}{l}1.023(0.939 \\
1.115)\end{array}$ & 0.499 & $\begin{array}{l}1.082(0.974 \\
1.201)\end{array}$ & 0.140 \\
\hline & DFI & $\begin{array}{l}1.041(0.973, \\
1.113)\end{array}$ & 0.245 & $\begin{array}{l}1.027(0.939 \\
1.123)\end{array}$ & 0.559 \\
\hline & ROS/MS & $\begin{array}{l}1.003(0.999 \\
1.007)\end{array}$ & 0.130 & $\begin{array}{l}1.006(1.000 \\
1.012)\end{array}$ & 0.055 \\
\hline
\end{tabular}

\section{Discussion}

During spermatogenesis, most of the cytoplasm is discarded while a proportion of mitochondria are retained in the midpiece of mature sperms to provide energy for flagellar beat[19]. The role of mitochondria in sperm function, especially sperm motility, has been widely noticed. It was reported that abnormal mitochondrial structures and functions, such as short midpieces, abnormal assemblies and membranous defects, were associated with poor seminal quality[20,21]. As an important component of mitochondria, mtDNA encodes 22 tRNAs, two rRNAs, and 13 proteins which are crucial for oxidative phosphorylation[22]. Mutations and deletions of mtDNA had been reported in asthenozoospermia and shown to be correlated to male infertility when they presented beyond a certain threshold level[23]. Besides, amplification of sperm mtDNA-CN was observed in sperm samples from infertile males[24].

Consistent with previous studies in various species[24-27], higher mtDNA-CN in abnormal sperms was observed in this study, and it was found to be negatively associated with sperm motility, concentration 
and morphology. Although the underlying mechanism remains unclear, the elevated mtDNA-CN in abnormal sperm might be explained by abnormal gene expression, mtDNA mutations/deletions and mitochondria per se. Firstly, abnormal expressions of gene which regulates mtDNA transcription and replication, such as mitochondrial transcription factor A (TFAM), might be responsible for the elevated mtDNA-CN. Since it was reported that TFAM expression was positively associated with mtDNA-CN and negatively correlated with sperm motility[28], therefore, increased TFAM expression would lead to the aberrant replication of mtDNA in abnormal sperms. Secondly, increased mtDNA-CN was probably to be a reflection or compensation of mitochondrial dysfunction caused by mtDNA mutations or deletions[2931]. Moreover, mtDNA-CN might be accumulated due to the imbalance between mitochondrial fusion and fission. In mitochondrial fission factor (Mff) mutant mice, sperm mitochondria failed to divide and mitochondrial sheaths were disjointed, resulting in abnormal sperm morphology and motility, and finally mice manifested as reduced fertility[32].

Except for mtDNA-CN, ROS/MS and DFI were also associated with seminal quality in our participants. ROS, a variety of oxygen-derived free radicals, were essential for sperm maturation, capacitation, hyperactivation, and acrosome reaction at low levels[33]. However, excess ROS would lead to oxidative stress and DNA damage in sperms, including DNA fragmentation, mtDNA damage, telomere attrition, epigenetic abnormalities, and $Y$ chromosome microdeletions[34]. In this study, ROS/MS was correlated with mtDNA-CN both in normal and abnormal sperms groups, while the association of ROS/MS and DFI was not observed (Supplemental figure S1). It indicated that the negatively effects of ROS on mtDNA might be more serious than nuclear DNA. Compared to nuclear DNA, mIDNA is adjacent to the ROS source and more susceptible to oxidative stress due to lack of protective histones and repair system. In the binary logistic regression analysis, the significance of ROS/MS was disappeared, and yet mtDNA and DFI were still associated with seminal quality. It was suggested that mtDNA and DFI were more predictive for seminal quality.

For embryo and pregnancy outcomes, it had been noticed that abnormal seminal quality had negatively paternal effects in IVF or ICSI procedures[5, 6, 35, 36]. However, the effects of sperm mtDNA-CN, DFI and ROS on embryo quality turned out to be ambiguous. In 2019, Wu et al. found sperm mtDNA-CN, as well as mtDNA deletions, were inversely associated with odds of fertilization and high-quality embryos after adjusting male age and measurement batches[12]. Besides, a prospective study of couples discontinuing contraception revealed that higher mtDNA-CN was associated with lower pregnancy probability[13]. On the contrary, it was recently reported that sperm mtDNA-CN was not a prognostic factor for fertilization, usable blastocyst development, and live birth rates in couples performed with ICSI[37]. In our cases performed with ART, mtDNA-CN was negatively associated with fertilization rate, but the significance was disappeared after adjusting male age, female age, seminal quality, and ART strategy, which suggested further studies of the role of mtDNA-CN in embryo development were needed.

The role of DFI had been investigated over a longer time span, and lots of meta-analyses and systematic reviews had summarized the effect of sperm DNA damage on clinical outcomes after IVF or ICSI[38-42]. Overall, there was a difference between outcomes of IVF and ICSI. Consistent in a majority of studies, no 
significant association of DFI and clinical outcomes was observed in ICSI. Nevertheless, the increased DFI would lead to a reduction in implantation rate and pregnancy rate and a declining trend in the live birth rate in IVF[42]. However, no correlations of DFI with embryo outcomes were observed whether in overall analysis or subgroup analysis in this study.

With regard to sperm ROS, it seems to have more effect on the embryo development instead of fertilization process[43]. Notwithstanding, negative associations of ROS with fertilization rate and pregnancy rate were also reported[11, 44]. Whereas, in this study, ROS/MS was not correlated with fertilization rate, cleavage rate and top-quality embryo rate, as well as clinical pregnancy rate.

\section{Conclusions}

In conclusion, sperm mtDNA-CN, ROS/MS and DFI were separately associated with sperm parameters, while elevated sperm mtDNA-CN and DFI jointly contributed to poor seminal quality. Moreover, mtDNA-CN was negatively correlated with fertilization rate in ART cases, which was not significant after adjusting male age, female age, seminal quality, and ART strategy. For pregnancy outcomes, sperm mtDNA-CN, ROS/MS and DFI were all not associated with clinical pregnancy rate. It is necessary to take further studies for determining the role of sperm mtDNA-CN, ROS/MS and DFI in embryonic and fetal development.

\section{Abbreviations}

\section{mtDNA-CN}

mitochondria DNA copy number

DFI

DNA fragmentation index

\section{ROS}

reactive oxygen species

ART

assisted reproductive technology

IVF

in vitro fertilization

ICSI

intracytoplasmic sperm injection

\section{CASA}

computer-assisted sperm analysis

qPCR

quantitative polymerase chain reaction

ROS/MS

ROS per million sperms

GLM 
generalized linear model

GEE

generalized estimating equations

OR

odds ratios

\section{Declarations}

\section{Ethics approval and consent to participate}

Written consent forms were obtained from all participants before sperms collecting. This study was approved by the IPMCH Ethics Review Committee and performed according to the Declaration of Helsinki.

\section{Consent for publication}

All authors review the final version of the manuscript and approve the submission and publication in Reproductive Biology and Endocrinology.

\section{Availability of data and material}

The datasets used or analyzed in the current study are available from the corresponding author on reasonable request.

\section{Competing interests}

All authors declare no conflict of interest.

\section{Funding}

This work is supported by the National Natural Science Foundation of China [NO. 81771638, 81971344, 81871136, 81501231]; Shanghai Municipal Health Commission [GW-10.1-XK07].

\section{Author contributions}

W.H. S and M.J. Y collected seminal samples and wrote the manuscript. Z.Y. Z and N.X. Q carried out the experiments and analyzed the data. X.Y. Z, N.X. X and S.C. C collected the clinical outcomes of participants. S.Y. $L$ and C.M. X designed the study and revised the manuscript.

\section{Acknowledgements}

We appreciate the support provided by the Youth Science and Technology Innovation Studio, Shanghai Jiao Tong University School of Medicine.

\section{References}


1. Inhorn MC, Patrizio P. Infertility around the globe: new thinking on gender, reproductive technologies and global movements in the 21st century. Hum Reprod Update. 2015;21:411-26.

2. Kushnir VA, Barad DH, Albertini DF, Darmon SK, Gleicher N. Systematic review of worldwide trends in assisted reproductive technology 2004-2013. Reprod Biol Endocrinol. 2017;15:6.

3. Imterat M, Agarwal A, Esteves SC, Meyer J, Harlev A. Impact of Body Mass Index on female fertility and ART outcomes. Panminerva Med. 2019;61:58-67.

4. Colaco S, Sakkas D. Paternal factors contributing to embryo quality. J Assist Reprod Genet. 2018;35:1953-68.

5. Liao QY, Huang B, Zhang SJ, Chen J, Chen G, Li KZ, Ai JH. Influence of Different Quality Sperm on Early Embryo Morphokinetic Parameters and Cleavage Patterns: A Retrospective Time-lapse Study. Curr Med Sci. 2020;40:960-7.

6. Shoukir Y, Chardonnens D, Campana A, Sakkas D. Blastocyst development from supernumerary embryos after intracytoplasmic sperm injection: a paternal influence? Hum Reprod. 1998;13:1632-7.

7. Yang Q, Zhao F, Dai S, Zhang N, Zhao W, Bai R, Sun Y. Sperm telomere length is positively associated with the quality of early embryonic development. Hum Reprod. 2015;30:1876-81.

8. Wyck S, Herrera C, Requena CE, Bittner L, Hajkova P, Bollwein H, Santoro R. Oxidative stress in sperm affects the epigenetic reprogramming in early embryonic development. Epigenetics Chromatin. 2018;11:60.

9. Borges E Jr, Zanetti BF, Setti AS, Braga D, Provenza RR, laconelli A Jr. Sperm DNA fragmentation is correlated with poor embryo development, lower implantation rate, and higher miscarriage rate in reproductive cycles of non-male factor infertility. Fertil Steril. 2019;112:483-90.

10. Durairajanayagam D, Singh D, Agarwal A, Henkel R. Causes and consequences of sperm mitochondrial dysfunction. Andrologia. 2021;53:e13666.

11. Zorn B, Vidmar G, Meden-Vrtovec H. Seminal reactive oxygen species as predictors of fertilization, embryo quality and pregnancy rates after conventional in vitro fertilization and intracytoplasmic sperm injection. Int J Androl. 2003;26:279-85.

12. Wu H, Whitcomb BW, Huffman A, Brandon N, Labrie S, Tougias E, Lynch K, Rahil T, Sites CK, Pilsner JR. Associations of sperm mitochondrial DNA copy number and deletion rate with fertilization and embryo development in a clinical setting. Hum Reprod. 2019;34:163-70.

13. Rosati AJ, Whitcomb BW, Brandon N, Buck Louis GM, Mumford SL, Schisterman EF, Pilsner JR. Sperm mitochondrial DNA biomarkers and couple fecundity. Hum Reprod. 2020;35:2619-25.

14. Zhang G, Yang W, Zou P, Jiang F, Zeng Y, Chen Q, Sun L, Yang H, Zhou N, Wang X, et al. Mitochondrial functionality modifies human sperm acrosin activity, acrosome reaction capability and chromatin integrity. Hum Reprod. 2019;34:3-11.

15. Anifandis G, Bounartzi T, Messini Cl, Dafopoulos K, Markandona R, Sotiriou S, Tzavella A, Messinis IE. Sperm DNA fragmentation measured by Halosperm does not impact on embryo quality and ongoing pregnancy rates in IVF/ICSI treatments. Andrologia. 2015;47:295-302. 
16. World Health Organization DoRHaR. WHO laboratory manual for the examination and processing of human semen Fifth edition. 2010:287.

17. Ye M, Shi W, Hao Y, Zhang L, Chen S, Wang L, He X, Li S, Xu C. Associations of mitochondrial DNA copy number and deletion rate with early pregnancy loss. Mitochondrion. 2020;55:48-53.

18. Veeck LL. Oocyte assessment and biological performance. Ann N Y Acad Sci. 1988;541:259-74.

19. Ho HC, Wey S. Three dimensional rendering of the mitochondrial sheath morphogenesis during mouse spermiogenesis. Microsc Res Tech. 2007;70:719-23.

20. Pelliccione F, Micillo A, Cordeschi G, D'Angeli A, Necozione S, Gandini L, Lenzi A, Francavilla F, Francavilla $S$. Altered ultrastructure of mitochondrial membranes is strongly associated with unexplained asthenozoospermia. Fertil Steril. 2011;95:641-6.

21. Gopalkrishnan K, Padwal V, D'Souza S, Shah R. Severe asthenozoospermia: a structural and functional study. Int J Androl. 1995;18(Suppl 1):67-74.

22. Anderson S, Bankier AT, Barrell BG, de Bruijn MH, Coulson AR, Drouin J, Eperon IC, Nierlich DP, Roe BA, Sanger $F$, et al. Sequence and organization of the human mitochondrial genome. Nature. 1981;290:457-65.

23. Vertika S, Singh KK, Rajender S. Mitochondria, spermatogenesis, and male infertility - An update. Mitochondrion. 2020;54:26-40.

24. May-Panloup P, Chrétien M, Fau - Savagner F, Savagner F, Fau - Vasseur C, Vasseur C, Fau - Jean M, Jean M, Fau - Malthièry $Y$, Malthièry $Y$, Fau - Reynier $P$, Reynier P. Increased sperm mitochondrial DNA content in male infertility. Hum Reprod. 2003;18:550-6.

25. Darr CR, Moraes LE, Connon RE, Love CC, Teague S, Varner DD, Meyers SA. The relationship between mitochondrial DNA copy number and stallion sperm function. Theriogenology. 2017;94:94-9.

26. Hesser A, Darr C, Gonzales K, Power H, Scanlan T, Thompson J, Love C, Christensen B, Meyers S. Semen evaluation and fertility assessment in a purebred dog breeding facility. Theriogenology. 2017;87:115-23.

27. Guo H, Gong Y, He B, Zhao R. Relationships between mitochondrial DNA content, mitochondrial activity, and boar sperm motility. Theriogenology. 2017;87:276-83.

28. Faja F, Carlini T, Coltrinari G, Finocchi F, Nespoli M, Pallotti F, Lenzi A, Lombardo F, Paoli DA-O. Human sperm motility: a molecular study of mitochondrial DNA, mitochondrial transcription factor A gene and DNA fragmentation. Mol Biol Rep. 2019;46:4113-21.

29. Al Zoubi MA-O, Al-Batayneh K, Alsmadi M, Rashed M, Al-Trad BA-O, Al Khateeb W, Aljabali A, Otoum O, Al-Talib M, Batiha OA-OX. 4,977-bp human mitochondrial DNA deletion is associated with asthenozoospermic infertility in Jordan. Andrologia. 2020;52:e13379.

30. Bahrehmand Namaghi I, Vaziri H. Sperm mitochondrial DNA deletion in Iranian infertiles with asthenozoospermia.. Andrologia 2017, 49.

31. Heidari MM, Khatami M, Danafar A, Dianat T, Farahmand G, Talebi AR. Mitochondrial Genetic Variation in Iranian Infertile Men with Varicocele. Int J Fertil Steril. 2016;10:303-9. 
32. Varuzhanyan G, Chen H, Rojansky R, Ladinsky MS, McCaffery JM, Chan DC. Mitochondrial fission factor (Mff) is required for organization of the mitochondrial sheath in spermatids. Biochim Biophys Acta Gen Subj. 2021;1865:129845.

33. Aitken RA-OX. Reactive oxygen species as mediators of sperm capacitation and pathological damage. Mol Reprod Dev. 2017;84:1039-52.

34. Bui AD, Sharma RA-O, Henkel RA-O, Agarwal AA-O. Reactive oxygen species impact on sperm DNA and its role in male infertility. Andrologia. 2018;50:e13012.

35. Janny L, Menezo YJ. Evidence for a strong paternal effect on human preimplantation embryo development and blastocyst formation. Mol Reprod Dev. 1994;38:36-42.

36. Parinaud J, Mieusset R, Vieitez G, Labal B, Richoilley G. Influence of sperm parameters on embryo quality. Fertil Steril. 1993;60:888-92.

37. Tiegs AW, Tao X, Landis J, Zhan Y, Franasiak JM, Seli E, Wells D, Fragouli E, Scott RT Jr. Sperm Mitochondrial DNA Copy Number Is Not a Predictor of Intracytoplasmic Sperm Injection (ICSI) Cycle Outcomes. Reprod Sci. 2020;27:1350-6.

38. Li Z, Wang L, Cai J, Huang H. Correlation of sperm DNA damage with IVF and ICSI outcomes: a systematic review and meta-analysis. J Assist Reprod Genet. 2006;23:367-76.

39. Zhao J, Zhang Q, Wang Y, Li Y. Whether sperm deoxyribonucleic acid fragmentation has an effect on pregnancy and miscarriage after in vitro fertilization/intracytoplasmic sperm injection: a systematic review and meta-analysis. Fertil Steril. 2014;102:998-1005.e1008.

40. Simon L, Zini A, Dyachenko A, Ciampi A, Carrell DT. A systematic review and meta-analysis to determine the effect of sperm DNA damage on in vitro fertilization and intracytoplasmic sperm injection outcome. Asian J Androl. 2017;19:80-90.

41. Deng C, Li T, Xie Y, Guo Y, Yang QY, Liang X, Deng CH, Liu GH. Sperm DNA fragmentation index influences assisted reproductive technology outcome: A systematic review and meta-analysis combined with a retrospective cohort study. Andrologia. 2019;51:e13263.

42. Ribas-Maynou J, Yeste M, Becerra-Tomás N, Aston KI, James ER, Salas-Huetos A. Clinical implications of sperm DNA damage in IVF and ICSI: updated systematic review and meta-analysis. Biol Rev Camb Philos Soc 2021.

43. Kuroda S, Takeshima T, Takeshima K, Usui K, Yasuda K, Sanjo H, Kawahara T, Uemura H, Murase M, Yumura Y. Early and late paternal effects of reactive oxygen species in semen on embryo development after intracytoplasmic sperm injection. Syst Biol Reprod Med. 2020;66:122-8.

44. Das S, Chattopadhyay R, Jana SK, Narendra BK, Chakraborty C, Chakravarty B, Chaudhury K. Cut-off value of reactive oxygen species for predicting semen quality and fertilization outcome. Syst Biol Reprod Med. 2008;54:47-54.

\section{Figures}


$\mathrm{OR}(95 \% \mathrm{Cl})$

$P$ Value

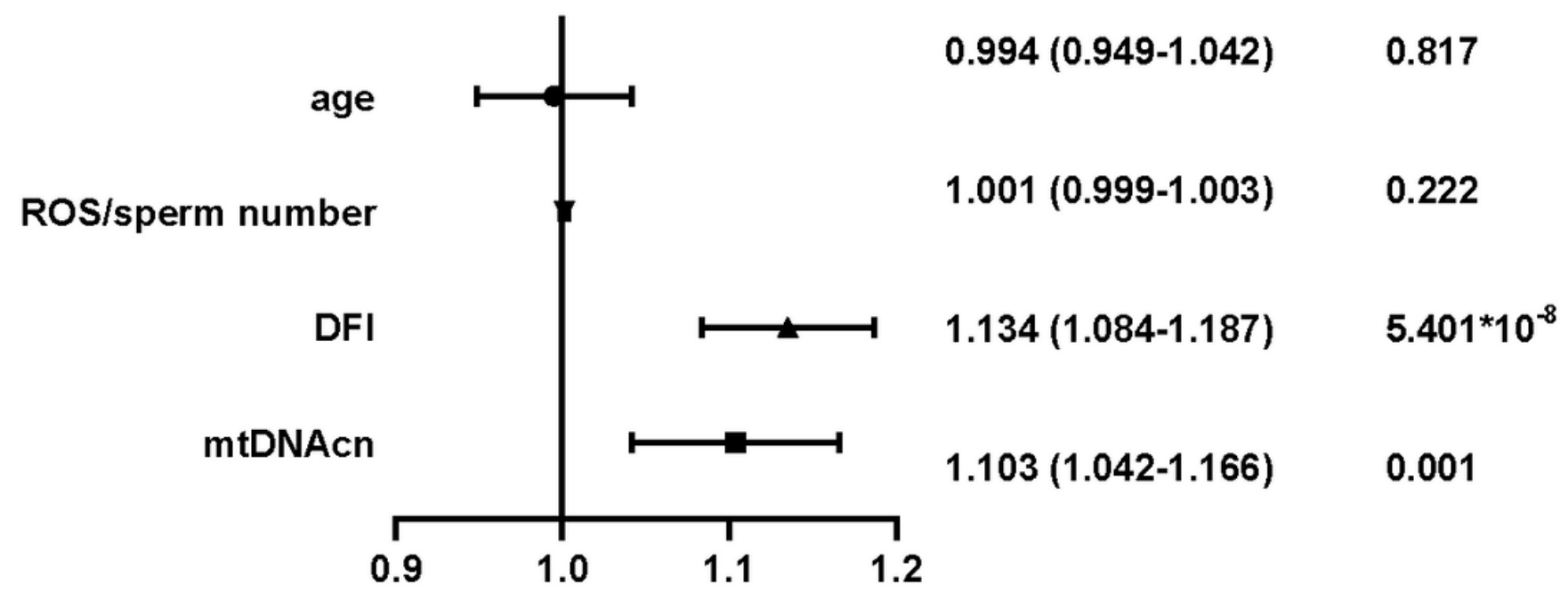

Figure 1

Associations of mtDNA-CN, DFI, ROS and male age with seminal quality.

\section{Supplementary Files}

This is a list of supplementary files associated with this preprint. Click to download.

- SupplementaryTables.docx

- supplementalfigure1.pdf

- supplementalfigure2.pdf

- supplementalfigure3.pdf 